\title{
Synchronous bilateral Wilms' tumor in the adolescent and adult
}

\author{
Report of the fifth case and review of the world literature
}

\author{
Peter B. Manning', Theodore Z. Polley Jr.', and Arnold G. Coran', 2 \\ ${ }^{1}$ Section of Pediatric Surgery, Mott Children's Hospital, University of Michigan, Medical Center \\ ${ }^{2}$ Department of Surgery, University of Michigan Medical School, Ann Arbor, MI 48109, USA
}

\begin{abstract}
Bilateral Wilms' tumor in the adolescent and adult is extremely rare, with only four previous cases reported. Theories as to the etiology of this entity and a review of the demographics, diagnosis, staging, and treatment of Wilms' tumor with emphasis on bilateral disease and the older patient are presented. Current approaches to the patient with an atypical presentation of Wilms' tumor can result in excellent results similar to those seen with the more typical presentation.
\end{abstract}

Key words: Bilateral Wilms' tumor - Wilms' tumor in the adult - Nephroblastomatosis

\section{Introduction}

Wilms' tumor is one of the most common intraabdominal malignancies of childhood, accounting for approximately $6 \%$ of intra-abdominal cancers presenting before the age of 15 years. The dramatic improvement in survival with this tumor over the past 25 years has been seen with few other malignancies. While the approach to the majority of patients with Wilms' tumor has become fairly well defined, some cases present with unusual features which make placement into a specific treatment protocol difficult. Bilateral, synchronous Wilms' tumor and Wilms' tumor in the adolescent and adult population are examples of such presentations. We report an adolescent with bilateral Wilms' tumor, a combination so rare that a review of the world literature has revealed only four previously reported cases, often with incomplete documentation. A review of the

Offprint requests to: T. Z. Polley, Jr etiology, demographics, diagnosis, staging, and treatment of Wilms' tumor with emphasis on bilateral disease in the adolescent and adult patient will be presented.

\section{Case report}

Our patient was a 15 -year-old white female when first referred to the University of Michigan Medical Center-Mott Children's Hospital in September 1983 for evaluation of bilateral renal masses. She had been well until March 1982 when she noted the onset of intermittent back pain. In May 1982, she developed severe left flank pain accompanied by nausea, vomiting, and pyrexia which resolved within 5 days. Over the ensuing 18 months, she had six similar acute episodes accompanied by a 7-kg weight loss. In August 1983, a left flank mass was palpable on physical examination and led to hospitalization. There was no history of trauma, hematuria, or dysuria and only occasional urinary frequency. Workup included renal ultrasound, which revealed bilateral renal masses, and Computer tomography (CT) scan confirmation of the presence of solid tumors involving both kidneys (Fig. 1). At this time, the only blood chemistry abnormality was an elevated LDH of 530 IU. Further evaluation at our institution included an intravenous pyelogram (IVP), which showed bilateral calyceal distortion (Fig. 2), and angiography, which suggested multiple hypovascular tumors originating in both kidneys (Figs. 3 and 4). On 30 August, 1983, exploratory laparotomy revealed bilateral renal tumors with no evidence of other intra-abdominal disease. The left kidney, as angiographically predicted, was nearly $100 \%$ replaced by tumor and the right side was approximately $50 \%-60 \%$ replaced. A left radical nephroureterectomy was performed after frozen section biopsy confirmed the diagnosis of Wilms' tumor. Final pathalogic evaluation revealed multifocal Wilms' tumor in the left kidney with predominantly epithelial histology. All 30 lymph nodes in the specimen were negative for neoplasm. Tumor deposits were noted, however, in the peripelvic fat. Postoperative chest $\mathrm{CT}$ and bone scan were negative. She was immediately begun on a combined chemotherapy regimen of actinomycin $D$ and vincristine, to which adriamycin was added after 1 month.

Serial CT scans showed a decrease in the size of the right renal tumor over the 3 months of treatment (Fig. 5). "Second look" laparotomy was performed on 1 December 1983 and re- 

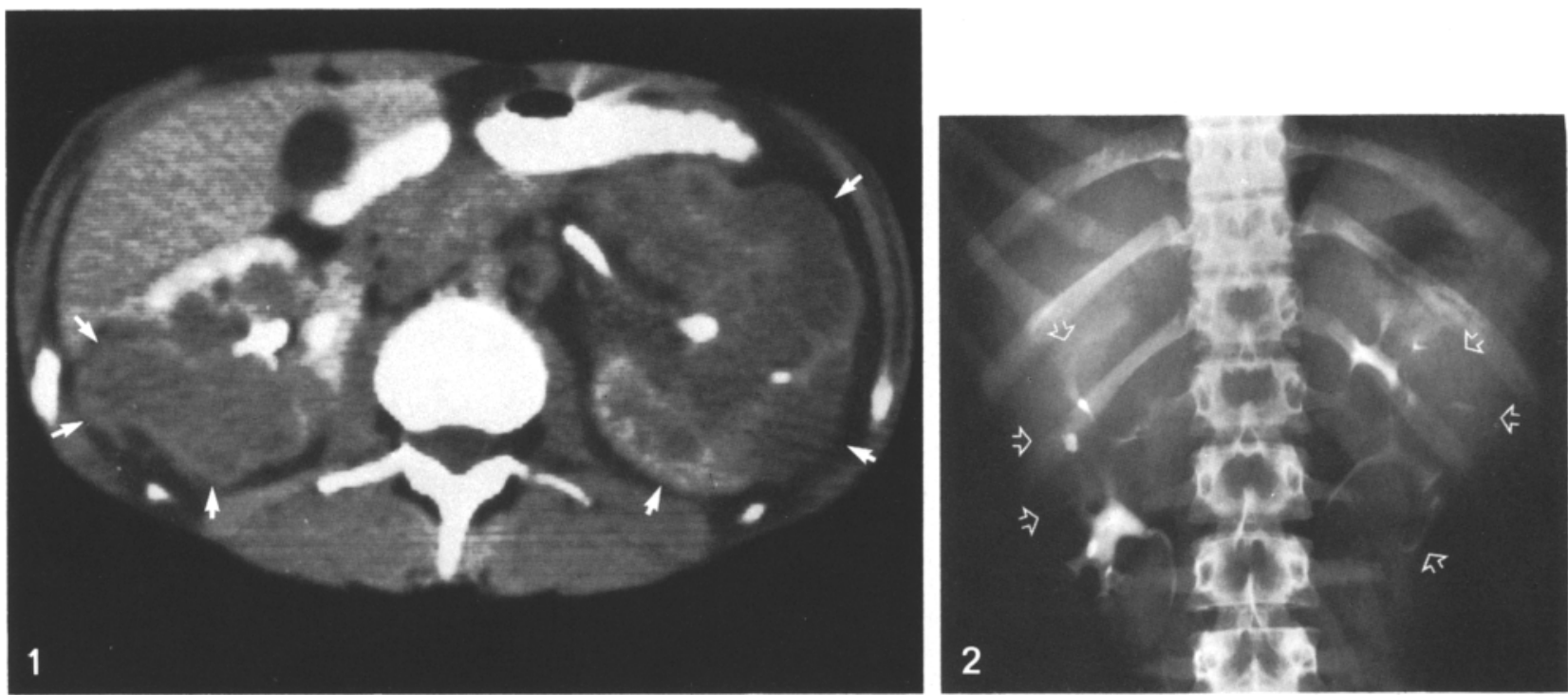

Fig. 1. CT scan demonstrating bilateral renal neoplasms

Fig. 2. IVP Shows calyceal distortion bilaterally due to intravenal neoplasm

vealed what appeared grossly to be a right renal upper pole "scar" with cystic changes throughout the remaining kidney. Partial nephrectomy was performed with removal of all gross tumor; pathologic evaluation of the specimen revealed both necrotic and viable Wilms' tumor in the upper pole mass. Biopsies from the remaining renal parenchyma showed the diagnosis of nephroblastomatosis. Postoperatively, the three-drug chemotherapy regimen was resumed. At no time did the patient develop renal insufficiency.

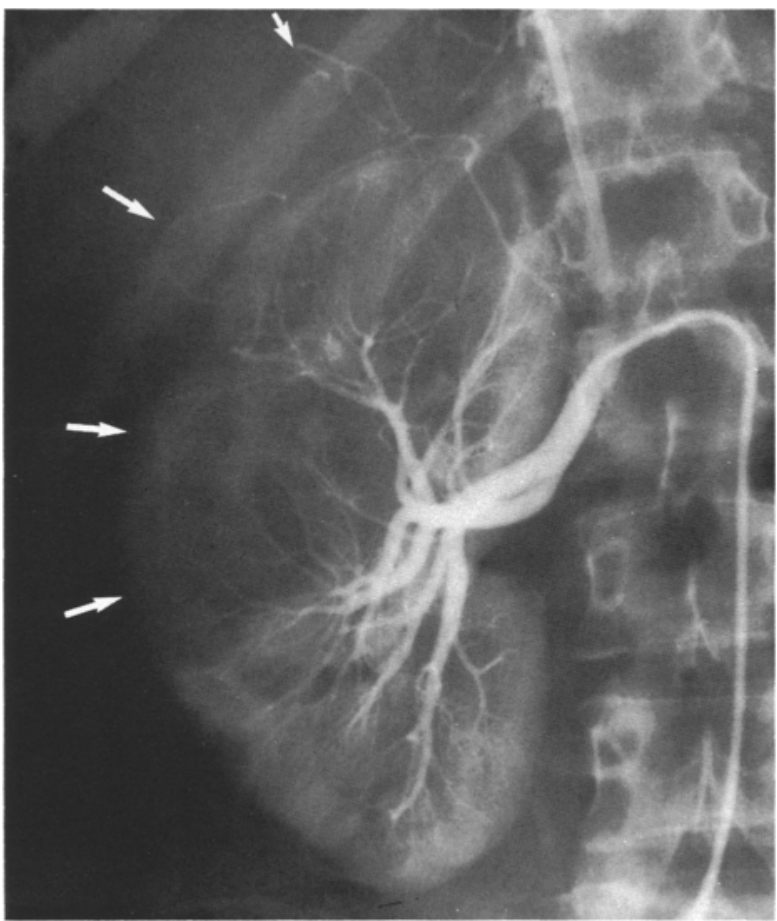

Fig. 3. Renal arteriogram (right) at presentation demonstrating involvement of upper two-thirds of right kidney
In May 1984, 9 months following her original operation, she developed recurrent right flank pain. Abdominal CT scan revealed right hepatic lobar and $\mathrm{T} 10$ vertebral metastases. Radiation to the lower thoracic spine was initiated and 2400 rads were administered. She was next treated with "lethal"-dose Melphalan followed by autologous bone marrow transplantation, which was complicated by an immune thrombocytopenia responsive to danazol and vincristine. CT scan in February 1985 showed sclerosis of the bony metatasis and enlargement

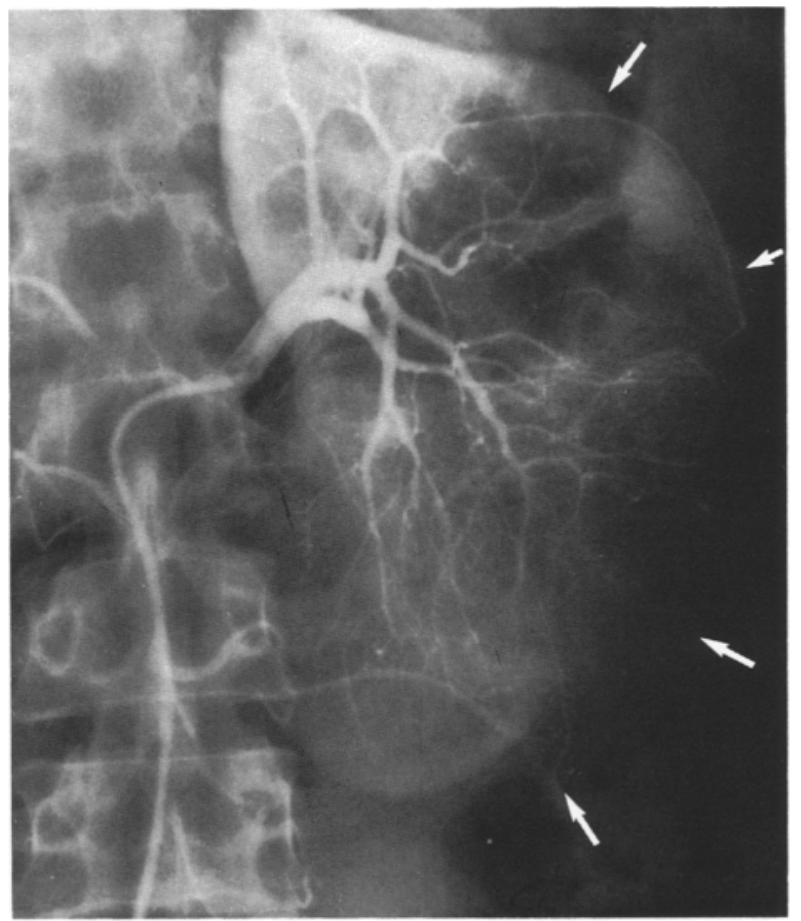

Fig. 4. Renal arteriogram (left) at presentation demonstrating near-total involvement by neoplasm 


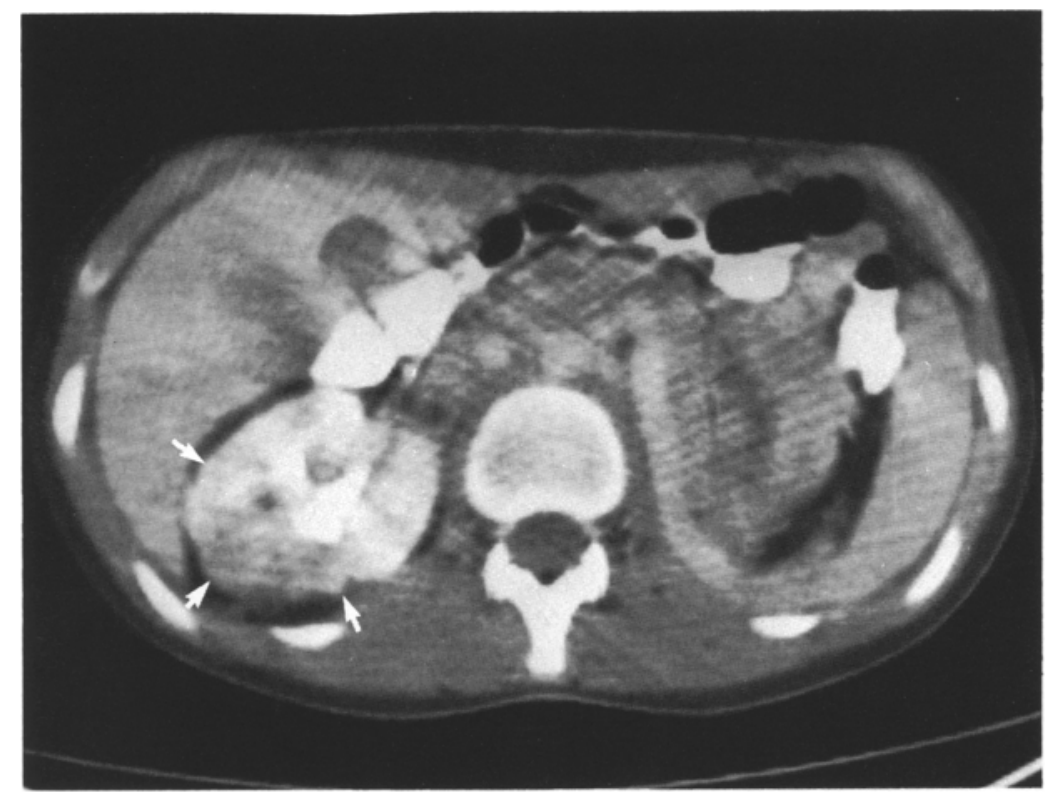

Fig. 5. Postoperative CT scan following left radical nephrectomy and combination chemotherapy demonstrating marked regresion of right renal neoplasm of the hepatic mass. The metastatic nature of the latter was confirmed by percutaneous biopsy and, as it represented the only evident focus of disease, right hepatic lobectomy was performed on 8 February 1985. The patient was undergoing a gradual recovery when she again developed severe thrombocytopenia refractory to all management and expired in March 1985,19 months after her initial diagnosis.

\section{Review of previous case reports}

Four cases of bilateral Wilms' tumor in the adolescent or adult, defined here as patients older than 12 years, have been previously reported in the world literature. Details of these cases are often obscure due to the historical nature of the reports or the need to translate from a foreign language. We have included all those cases for which reasonable data was available.

Case 1. Battendorf [4], in a 1970 report translated from the German literature, described a 59-yearold female who presented with right pulmonary hilar prominence, dizziness, right hemiparesis, microscopic hematuria, and proteinuria. She was presumed to have lung cancer with central nervous system metastatic disease and became comatose and died without further therapy. At postmortem examination, bilateral upper pole renal masses were detected which proved histologically to be Wilms' tumor with "glomerular differentiation". This was accompanied by renal venous and inferior vena caval thromboses and tumor involvement of hilar nodes. In addition, there were cerebral metastases accompanied by signs of increased intracranial pressure.
Case 2. This case is included in the report of a series of 1,351 cases of Wilms' tumor by Klapproth et al. [28] from 1959, which included 45 cases from the Cleveland Clinic diagnosed and treated between 1921 and 1953. A 29-year-old female was first treated in 1943, at age 17 years, with radiation therapy for a right renal neoplasm described as "spindle cell sarcoma arising from the nerve and smooth muscle". She was seen again in 1956 at the Cleveland Clinic for evaluation of hypertension. An IVP at that time revealed a right renal neoplasm and she underwent exploratory laparotomy with nephrectomy for a tumor pathologically identified as Wilms' tumor. She suffered a number of postoperative complications related in part to her previous radiation therapy and died 5 months after surgery. Postmortem examination revealed that the remaining kidney was almost completely replaced by neoplasm, again histologically Wilms' tumor. This case is included to ensure completeness, recognizing that these findings could represent metastasis to the remaining kidney as well as asychnronous neoplasia.

Case 3. Knudson et al. [29] reviewed 97 cases of Wilms' tumor from the M. D. Anderson Hospital between 1944 and 1970 . In this report, a notation is made of bilateral Wilms' tumor in a patient over 12 years of age. No further details are available.

Case 4. Tsunoda et al. [44], in 1969, reviewed the Japanese literature and reported 19 cases of bilateral Wilms' tumor. The author cited a report by 
Fugita [21] of an 18-year-old female with synchronous bilateral Wilms' tumor who was diagnosed in 1928 and treated with a right nephrectomy but expired, presumably of her disease. No further details are available.

\section{Discussion}

\section{Demographics}

The incidence of Wilms' tumor has been noted to be remarkably stable and without geographic preference occurring at a rate of approximately 7.8 per million children under 15 years of age [14]. It ranks fifth in frequency among the solid tumors of childhood behind CNS tumors, lymphoma, neuroblastoma, and soft tissue sarcoma [40]. While $95 \%$ of cases are diagnosed before age 10 , with a peak incidence at age 3 , cases have been documented in the fetus and in adults up to the age of 80 years.

The incidence of Wilms' tumor in adults is difficult to determine, although there appears to be a peak in the 4th decade. Recent reviews [3, 27] have noted close to 200 cases of Wilms' tumor in adults and adolescents over 12 years of age, but authors report that in many of these cases the diagnosis is questionable. Kilton [27] reviewed 35 cases of adult Wilms' tumor in 1980 that in his opinion were the only cases in the world literature with adequate documentation.

Bilateral involvement was first reported by Rance [42] in 1814: a case which represents the earliest description of Wilms' tumor. Recent reviews place the frequency of bilaterality at between $1 \%-12 \%$ of all cases, with most larger series estimating the rate at approximately $5 \%[6,10]$. Two-thirds of bilateral cases present synchronously; the remainder are typically diagnosed from 2 years to as long as 19 years after the initial tumor. Synchronous, bilateral disease tends to present at a younger age than does unilateral disease (30 months vs 45 months) $[7,10,29]$.

There is an increased incidence of congenital anomalies in patients with Wilms' tumor. Specifically, these include hemihypertrophy, aniridia, and various genitourinary anomalies [37]. This frequency of congenital anomalies may be up to ten times higher in cases of bilateral Wilms' tumor, especially with regard to hemihypertophy and hypospadias [10].

\section{Etiology}

Because of its histologic resemblance to embryonic renal tissue (classically with epithelial, blastemal, and stromal elements), it is speculated that
Wilms' tumor is associated with nephroblastomatosis, which represents the persistence of immature renal tissue beyond the time of completion of nephrogenesis (36 weeks) [33]. The pathology literature is often confusing and describes a number of histologic variants of nephroblastomatosis which could be associated with Wilms' tumor, including nodular renal blastema, sclerosing metanephric hamartomas, Wilms' tumorlets, and glomerular immaturity with sclerosis [8]. Examination of multiple sections of kidneys with Wilms' tumor has shown nephroblastomatosis in a significant percentage of cases, leading to the belief that this represents a precursor lesion [8, 33]. In these studies, all cases of bilateral tumor showed evidence of nephroblastomatosis, supporting the hypothesis that this multicentric abnormality may be particularly important in the occurrence of multifocal neoplasia. This finding further supports the view that bilateral Wilms' tumor represents multiple primary tumors rather than metastasis from the contralateral kidney.

Another area of great interest related to the origin of Wilms' tumor is that of genetic heritability. Through analysis of familial cases of Wilms' tumor as well as cases of unilateral, bilateral, and multifocal neoplasm, a theory of heritability of this entity has been developed and widely accepted [30]. This theory is based on a two-step mutational model and predicts that hereditary cases may account for $20 \%-38 \%$ of Wilms' tumor cases [29]. The theory proposes that non-hereditary cases result from two somatic (postzygotic) mutations in a cell, yielding a single unifocal tumor. In the heritable case, the first mutation is in the germinal cell line which is prezygotic and, therefore, affects all cells in the patient. A single additional postzygotic mutation in the target tissue would then be necessary for manifestation of the tumor. From such a model, one would expect a younger age of presentation for patients with inherited tumors as well as an increased frequency of bilateral as well as multifocal unilateral tumors among the patients with this heritable form. Nephroblastomatosis may represent the phenotypic expression of the proposed first mutation.

There are several lines of evidence from clinical reviews supporting such a theory. First, the average age of presentation has been shown to be lower in bilateral and familial cases [29], although a more recent study [10] has not substantiated this in familial cases. Second, there is an increased prevalence of associated anomalies with well demonstrated heritability in Wilms' tumor patients. Finally, a specific chromosomal abnormality, de- 
letion of the p13 band of chromosome II, has been identified in a number of Wilms' patients, particularly in association with aniridia [40]. The bulk of the evidence supports the theory of heritability as autosomal dominant with incomplete penetrance, with bilaterality expected in $15 \%$ of heritable cases. That bilaterality in the older patient is markedly unique is predicted by these theories.

\section{Diagnosis}

The most common presenting symptoms in the patient with Wilms' tumor are abdominal mass, pain, hematuria, fever, and hypertension [40]. While a mass lesion is the most frequent finding in the typical pediatric patient $(90 \%)$, in adults abdominal pain is the most frequent complaint $(60 \%)$ followed by abdominal mass $(48 \%)$ and hematuria (36\%) [27]. In as many as $42 \%$ of adult patients, the symptoms have been present for greater than 1 year prior to diagnosis [27]. Hematuria and hypertension have been noted to be more frequent in cases of bilateral disease [2].

In the past, the IVP has been the mainstay of evaluation of the patient with Wilms' tumor, typically revealing calyceal distortion and displacement, with ultrasound used frequently to confirm the renal origin and solid nature of the abdominal mass. Angiography is not used routinely in these patients, but may be useful in older patients where the diagnosis is unclear or in bilateral cases to assess the feasibility of heminephrectomy [24,

Table 1. NWTS staging system

\begin{tabular}{ll}
\hline Stage I & $\begin{array}{l}\text { Tumor limited to kidney, completely excised; } \\
\text { capsular surface intact, no rupture, no residual } \\
\text { tumor at margins of resection }\end{array}$ \\
Stage II & $\begin{array}{l}\text { Tumor extends beyond the kidney but is com- } \\
\text { pletely excised; penetration through capsule } \\
\text { into perinephric soft tissues; renal vessels may } \\
\text { contain tumor; previous biopsy or local opera- } \\
\text { tive flank; no residual tumor at margins of } \\
\text { resection } \\
\text { Residual nonhematogenous tumor is confined } \\
\text { to the abdomen } \\
\text { a. any abdominal lymph nodes involved } \\
\text { b. diffuse peritoneal contamination second- } \\
\quad \text { ary to rupture or spillage } \\
\text { c. peritoneal implants } \\
\text { d. tumor grossly or microscopically beyond } \\
\text { surgical margin } \\
\text { e. tumor not completely resectable due to } \\
\text { infiltration of vital stuctures }\end{array}$ \\
Stage IV & $\begin{array}{l}\text { Hematogenous metastases present (lung, liver, } \\
\text { bone, CNS) } \\
\text { Stage V }\end{array}$ \\
Bilateral renal involvment
\end{tabular}

36]. CT scanning has emerged as possibly the single most usefull study in the evaluation of the patient with bilateral Wilms' tumor. With contrast infusion, CT can reveal the extent of the tumor mass and renal functional status as well as vena caval patency, and can also demonstrate the presence of metastatic disease. It is of critical importance for follow-up [9]. In cases of bilaterality, it has been shown to be quite sensitive in the preoperative assessment of feasability of partial nephrectomy [13]. In the older patient group, intraoperative biopsy is often needed to conclusively make the diagnosis; percutaneous biopsy is contraindicated where Wilms' tumor is suspected due to the risk of tumor spread, which may adversely affect prognosis.

Prior to the advent of CT, as many as $30 \%-50 \%$ of cases of bilateral Wilms' tumor were unsuspected prior to operation. Surgical exploration, therefore, was critical not only for treatment but also for diagnosis. Complete visual and manual inspection of the contralateral kidney via reflection of the colon and opening of Gerota's fascia was emphasized at least 25 years ago [35], and is commonly performed today to ensure proper investigation of the possibility of bilateral disease.

\section{Classification/staging}

The cooperative National Wilms' Tumor Study (NWTS) has developed the most widely used system for grouping patients based on factors of prognostic significance. From the results of the first two phases of the study, some modifications

Table 2. TNM system for Wilms' tumor staging

\begin{tabular}{ll}
\hline $\mathrm{T}-1$ & $\begin{array}{l}\text { Tumor encapsulated; less than } 550 \mathrm{cc} \text {; no } \\
\text { capsular, collecting system, or major vascular } \\
\text { invasion; complete surgical removal }\end{array}$ \\
$\mathrm{T}-2$ & $\begin{array}{l}\text { Tumor exceeds one or more of above criteria } \\
\text { but is apparently totally excised }\end{array}$ \\
$\mathrm{T}-3$ & $\begin{array}{l}\text { Tumor is massive, invades other organs, } \\
\text { and/or cannot be totally excised }\end{array}$ \\
$\mathrm{N}-0$ & $\begin{array}{l}\text { No nodes involved } \\
\mathrm{N}-1\end{array}$ \\
$\mathrm{M}-0$ & Hiar or para-aortic lymph nodes positive \\
$\mathrm{M}-1$ & No non-nodal metastases \\
$\mathrm{M}-2$ & Pulmonary metastases only \\
\end{tabular}

Clinical stage correlation with TNM stage

Stage $I=T_{1} N_{0} M_{0}$

Stage II $=\mathrm{T}_{1} \mathrm{~N}_{1} \mathbf{M}_{0}$ or $\mathrm{T}_{2} \mathrm{~N}_{1} \mathbf{M}_{\mathbf{0}}$

Stage III $=\mathrm{T}_{3} \mathrm{~N}_{0} \mathrm{M}_{0}$ or $\mathrm{T}_{3} \mathrm{~N}_{1} \mathrm{M}_{0}$

Stage IV $=$ any $T$, any $N, M_{1}$

Stage $\mathrm{V}=$ any $\mathrm{T}$, any $\mathrm{N}, \mathrm{M}_{2}$ 
have been adopted to make it a true staging scheme (Table 1) [15]. In addition to the factors noted in the grouping system, separate stratification is based on histologic findings. Approximately $11 \%$ of patients exhibit anaplastic or sarcomatous elements in their tumor classifiying them as "unfavorable histology". The remainder demonstrate more typical histology with varying degrees of epithelial, blastemal, or stromal differentation and are classified as "favorable histology". The prognosis for patients with unfavorable histology is significantly worse than that for those with favorable histology. This system is applicable to patients regardless of age, although advanced age may be a negative prognostic indicator.

A TNM system has also been developed for Wilms' tumor, although it has not been employed in NWTS analyses (Tables 1 and 2) [12, 22]. The NWTS staging system places all patients with bilateral disease in group $\mathrm{V}$ without regard to prognostic factors that separate patients into the other groups. The TNM system, however, has been used by some to further stratify patients with bilateral disease basing their stage on the side of most significant involvement $[34,46]$. Using this method in a review of 20 bilateral cases, Malcom et al. [34] showed that survival in this group is related to the same prognostic factors as in unilateral disease and suggest that survival in synchronous bilateral disease is no different than similarly staged cases of unilateral disease.

\section{Treatment}

Before 1960 , treatment of Wilms' tumor was limited primarily to surgery, radiation, or both with reasonable results. Since 1960 , an aggressive multimodal approach combining surgery, radiation, and chemotherapy has improved the outcome from overall survivals of approximately $30 \%$ to $80 \%-90 \%$ in stages I and II. The NWTS has been instrumental in defining and standardizing the optimal treatment of patients classified in groups I-IV. Surgery typically involves radical transperitoneal nephroureterectomy with thorough exploration of the abdomen, including the contralateral kidney. Care in handling the tumor is stressed to avoid capsular rupture [32]. Radiation, when indicated, is delivered to the renal fossa, with total abdominal radiation limited to cases with diffuse tumor spillage or peritoneal implants. Chemotherapy is begun in the immediate postoperative period and consists of actinomycin $D$ and vincristine. Evaluation of the benefit of adding adriamycin and/or cyclophosphamide in more advanced stages is ongoing [15].
The principles and regimens set forth in the NWTS protocols are generally applicable to the adult and adolescent patient. There is limited evidence that actinomycin D may not be as effective in adults as it is in children, but most authors nonetheless recommend its use [46]. The rarity of the disease in this age group makes a comparative analysis between adults and children difficult, and specific recommendations regarding the treatment of adults have been developed via extrapolation from data on pediatric patients.

Principles for the management of bilateral Wilms' tumor have undergone significant evolution, but no universally accepted scheme exists yet. Strict adherence to the algorithims for unilateral disease would jeopardize renal function on the basis of both extensive surgical excision and the possibility of radiation-induced nephritis. In earlier years, the major controversies centered on the choice of immediate resection with or without perioperative radiation versus the exclusive use of radiation therapy [5]. The results of early surgical intervention followed by agressive adjuvant therapy in unilateral disease has prompted most centers to adopt a plan of early exploration in bilateral disease.

Most current approaches involve an attempt at total gross tumor excision in one, two, or three stages followed at each stage by chemotherapy and radiation when indicated. When surgically feasible, this will result in total nephrectomy with contralateral heminephrectomy or bilateral heminephrectomy. This approach is possible in only about $50 \%$ of cases because of massive or multifocal involvement of both kidneys. In these cases, regimes of chemotherapy and radiation are used along with liberal surgical re-exploration to control the remaining tumor.

Bilateral nephrectomy and allotransplantation for Wilms' tumor was first reported in 1968 and has since been advocated by a number of groups as an acceptable choice of therapy $[17-19,39]$. One review showed significantly lower survival in transplanted patients ( $29 \%$ vs $67 \%)$, with most of the excess mortality secondary to septic complications [19]. Delaying transplantation beyond 1 year following the initial treatment significantly reduced the incidence of such complications. Another study noted a higher recurrence rate in patients treated with transplantation within 1 year following bilateral nephrectomy and recommended a 1-2-year delay in transplantation if feasible [39]. Newer immunosuppresive therapy may significantly affect these results.

In general, treatment of bilateral Wilms' tu- 
mor must be highly individualized and, based on recent reviews, may be summarized as follows [6, $18,47]$ : in all caes of Wilms' tumor, both kidneys should be thoroughly palpated or inspected. Originally, surgical attitudes favored gross total removal of tumor by nephrectomy, nephrectomy plus contralateral partial nephrectomy, or bilateral partial nephrectomy while sparing enough tissue $(15 \%-35 \%)$ [41] to ensure adequate renal function. More recent publications [26] suggest that a more conservative surgical approach may be appropriate, stressing biopsy at initial exploration with subsequent second-and third-look operations and preservation of at least $60 \%$ of renal tissue. The use of chemotherapy and radiation depends upon the stage of the more involved side as dictated by the NWTS protocols. Radiation doses must be adjusted to limit exposure of any remaining renal tissue to 1500 rads. If gross total removal is impossible, chemotherapy and radiation should begin immediately and a second-look procedure should be performed, generally following 3 months of treatment. This may be variable and depends upon the patient's response as judged by noninvasive evaluation. Bilateral nephrectomy and subsequent transplantation should be reserved for patients with otherwise unresectable tumor who do not respond well to the other treatment regimens.

\section{Prognosis}

Early in this century, survival for all cases of Wilms' tumor was less than 10\% [31]. During the first half of the century, overall survival improved to $40 \%-50 \%$; however, cures remained uncommon in adults or patients with bilateral disease $[15,25,42,43]$. With combined multimodal therapy, which has become standard since the 1960's. 2-year survival has increased to $95 \%$ in stage I patients $[16,38]$. Survival rates in adults have been estimated to be $44 \%$ at 18 months [27]; however, lack of standardization of therapy and delay in diagnosis have undoubtedly influenced these results unfavorably. Many authors feel that the same results seen in children are attainable in adults with early diganosis and aggressive management $[1,15]$. In patients with bilateral disease, improvement in survival has been noted to parallel the overall improvement in Wilms' tumor treatment from $13.8 \%$ reported in the early 1970's [20] to $67 \%-87 \%$ in more recent reviews $[6,19,23$, 24]. Some controversy still exists as to whether synchronous and metachronous cases of bilateral Wilms' tumor represent two separate entities with different prognostic implications. One report has shown reduced survival in patients with metachronous presentations [34] while another shows no difference other than that seen in similarly staged synchronous bilateral or unilateral cases [11].

In conclusion, the coincidence of these two unusual presentations (bilaterality in an adolescent) for Wilms' tumor is extremely rare. We have been able to identifity four cases in the world literature, with no cures reported $[4,28,30,44]$. In at least two of these four previously reported cases, diagnosis was made at postmortem examination. Details were insufficient to reveal how the diagnosis was made in the other two patients; similar difficulties are encountered in reviewing staging and therapeutic planning in these patients.

Bilateral Wilms' tumor in older patients is extremely rare, and successful treatment hinges on early diagnosis. Rational approaches for the management of bilateral disease continue to evolve; however, the lack of standardized substaging in this group will continue to preclude a meaningful comparison of the various treatment regimens.

\section{References}

1. Adolphs HD, Knopfle G, Vogel J, Hartlapp J (1983) Wilms' tumor in the adolescent and the adult. Eur Urol 9: 281-287

2. Alvarado CS, Verras A, Ragab AH (1984) Bilateral Wilms'. In: Pachedly C, Baum ES (eds) Wilms' tumor: clinical and biological manifestations. Elsevier Science Publishing Co, New York, pp 89-102

3. Babaian RJ, Skinner DG, Waisman J (1980) Wilms' tumor in the adult patient. Cancer 45: 1713-1719

4. Bettendorff U (1973) Bilateral Wilms' tumor in the adult. Zentralbl Allg Pathol 117: 394-399

5. Bishop HC, Hope JW (1966) Bilateral Wilms' tumor. J Pediatr Surg: $476-487$

6. Bishop HC, Tefft M, Evans AE, D'Anigo GJ (1977) Survival in bilateral Wilms' tumor - review of 30 National Wilms' Tumor Study cases. J Pediatr Surg 12: 631-638

7. Bond JV (1975) Bilateral Wilms' tumor. Lancet III 482-484

8. Bove KE, McAdams AJ (1976) The nephroblastomatosis complex and its relationship to Wilms' tumor: a clinicopathologic treatise. Perspect Pediatr Pathol 3: 185-223

9. Brasch RC, Randal SB, Gould RG (1981) Follow-up of Wilms' tumor: comparison of CT with other imaging procedures. AJR 137: 1005-1009

10. Breslow NE, Beckwith JB (1982) Epidemiological features of Wilms' tumor: results of the National Wilms' Tumor Study. J Natl Cancer Inst 68: 429-436

11. Casale AJ, Flanigan RC, Moore PJ, McRoberts JW (1982) Survival in bilateral metachronous (asynchronous) Wilms' tumor. J Urol 128: 766-769

12. Cassaday JR, Tefft M, Filler RM, Paed D, Hellman S (1973) Considerations in the radiation therapy of Wilms' tumor. Cancer 32: 598-608

13. Cohen MD, Weber T, Smith JA, Reider JR (1983) The role of computerized tomography in the diagnosis and 
management of patients with bilateral Wilms' tumor. J Urol 130: 1160-1162

14. Cutter SJ, Young JL Jr (eds) (1975) The third national cancer survey, incidence data. National eancer test monogr 41 (1)

15. D'Angio GJ, Beckwith JB, Breslow NE, Bishop HC, Evans AE, Farewell V, Fernbach D, Goodwin WE, Jones B, Leape LL, Palmer NF, Tefft M, Wolff JA (1980) Wilms' tumor: an update. Cancer 45: 1791-1798

16. D'Angio GJ, Evans AE, Breslow NE, Beckwith B, Bishop HC, Farewell V, Goodwin W, Leape L, Palmer N, Sinks L, Sutow W, Tefft M, Wolff J (1981) The treatment of Wilms' tumor: results of the second National Wilms' 'Tumor Study. Cancer 46: 2302-2311

17. David HS, Lavengood RW Jr (1974) Bilateral Wilms' tumor: treatment, management and review of the literature. Urology 3: 71-74

18. deLormier AA, Belzer FO, Kountz SL, Kushner J (1971) Treatment of bilateral Wilms' tumor. Am J Surg 122: $275-281$

19. DeMaria JE, Hardy BE, Brezinski A, Churchill BM (1979) Renal transplantation in patients with bilateral Wilms' tumor. J Pediatr Surg 14: 577-579

20. Fay R, Brosman S, Williams DI (1973) Bilateral nephroblastoma. J Urol 119: 124

21. Fugita M, Matano I (1928) A case of mixed tumor of the kidney combined with tubular sclerosis of brain. J KyotoUritsu Med Col (Kyoto) 3: 297-308

22. Garcia M, Douglass C, Schlosser JV (1963) Classification and prognosis in Wilms' tumor. Radiology 80: 574-580

23. Garrett RA, Donohue JP (1978) Bilateral Wilms' tumors. J Urol 120: 586-588

24. Hartman DS, Davis CJ Jr, Madewell JE, Friedman AC (1982) Primary malignant renal tumors in the second decade of life: Wilms' tumor vs renal cell cancer. J Urol 127 : $888-891$

25. Jagasia KH, Thurman WA, Pickett E, Grabstaldt (1964) Bilateral Wilms' tumors in children. J Pediatr 65: 371-376

26. Kay R (ed) 1985) Bilateral Wilms' tumor. Dialogues Pediatr Urol 8: 1-8

27. Kilton L, Mathews MJ, Cohen MH (1980) Adult Wilms' tumor: a report of prolonged survival and review of the literature. J Urol 124: 1-5

28. Klapproth HJ (1959) Wilms' tumor: a report of 45 cases and an analysis of 1351 cases reported in the world literature from 1940-1958. J Urol 81:633-648

29. Knudson AG (1980) Genetics and the child cured of cancer. In: van Eys J, Sullivan MP (eds) Status of curability of childhood cancer. Raven Press, New York, pp 295-305

30. Knudson AG, Strong LC (1972) Mutation and cancer: a model for Wilms' tumor of the kidney. J Natl Cancer Inst 48: $313-324$
31. Ladd WE (1938) Embryoma of the kidney (Wilms' tumor). Ann Surg 108: 885-902

32. Leape LL, Breslow NE, Bishop HC (1978) The surgical treatment of Wilms' tumor: results of the National Wilms' Tumor Study. Ann Surg 187: 351-356

33. Machin GA (1980) Persistent renal blastema (nephroblastomatosis) as a frequent precursor of Wilms' tumor. A pathalogical and clinical review. Am J pediatr Hematol Oncol 2: $165-172,253-261,353-362$

34. Malcolm AW, Jaffe N, Folkman MJ, Cassady JR (1980) Bilateral Wilms' tumor. Intl J Radiol Oncol Biol Phy 6: $167-174$

35. Martin LW, Kloecker RJ (1961) Bilateral nephroblastoma (Wilms' tumor). Pediatrics 28: 101-106

36. Meng C-H, Elkin M (1969) Angiographic manifestations of Wilms' tumor. AJR 105:95-104

37. Miller RW, Fraumeni JF, Manning MD (1964) Association of Wilms' tumor with aniridia, hemihypertrophy, and other congenital malformation. $N$ Engl J Med 270: 922-927

38. Morris-Jones PH (1983) Wilms' tumor. Recent Results Cancer Res 88: 79-88

39. Penn I (1979) Renal transplantation for Wilms' tumor: report of 20 cases. J Urol 122: 793-794

40. Greenwood MF, Holland P (1984) Clinical and biochemical manifestations of Wilms' tumor. In: Pochedly $C$, Baum ES (eds) Elsevier Science Publishing Co, New York, pp 9-30

41. Ragab AH, Vietti TJ, Crist W, Perez C, McAllister W (1972) Bilateral Wilms' tumor. A review. Cancer 30: 983-988

42. Rance TF (1814) Case of fungus haematodes of the kidneys. Med Phys J 32: 19-25

43. Scott LS (1955) Bilateral Wilms' tumor. Br J Surg 42: $513-516$

44. Tsunda A, Ishida M, Ohmi K (1969) Bilateral Wilms' tumor: a case report and a survey of nineteen cases in the Japanese literature. Acta Paediatr Ph II: 1-7

45. Vats TS, Seeman J (1982) Bilateral Wilms' tumor. A case report an review of the literature. J Kains Med Soc 82: $631-633$

46. Vortsman B, Rothwell D (1982) Wilms' tumor in the adult patient. Urology $20: 628-630$

47. Wasiljew BK, Besser A, Raffensperger J (1982) Treatment of bilateral Wilms' tumors: a 22-year experience. J Pediatr Surg 17: 265-268

Received July 17, 1986 